\title{
Clinical Findings In 111 Ex-Porton Down Volunteers
}

\author{
HA Lee, R Gabriel, AJ Bale, D Welch
}

\begin{abstract}
Objective

To determine whether the health of Porton Down volunteers (PDV) has suffered as a result of their participation in medical trials, during which they were exposed to single low dose concentrations of chemical warfare agents.
\end{abstract}

\begin{abstract}
Methods
Data were obtained from a self-selected series of ex-Porton Down volunteers who attended the MOD's Porton Down Volunteers' Medical Assessment Programme (PDVMAP). One hundred and eleven men attended with a mean age of 62 (range 37-81) years. Information obtained was analysed to determine whether clinical diagnoses and symptoms reported had any relationship to chemical exposures.
\end{abstract}

\section{Results}

The diagnoses were not unusual for UK nationals with a mean age of 62 years. The majority of volunteers went to Porton Down in the 1950s and then had a mean age of 19 . The mean time between volunteers attending Porton Down and coming to MAP was 42 years. We found no correlation between chemical exposures and later development of established diagnoses, a latent period of 30 years.

\section{Conclusion}

On a clinical basis, no evidence was found to support the hypothesis that participation in Porton Down trials produced any long-term adverse health effects or unusual patterns of disease compared to those of the general population of the same age.

\section{Roger Gabriel \\ Consultant Physician}

Amanda J Bale

Database Manager

Dawn Welch

Database Assistant

Baird Health Centre, Gassiot House St Thomas' Hospital London SE1 7EH E-mail:

map@gstt.sthames.nhs.uk

\section{Introduction}

The Service Volunteer Programme at Porton Down came into existence in 1916 and since then over 20,000 volunteers from the three Armed Services (Army, Royal Navy and Royal Air Force) have taken part in various studies. During the period from 1916 to the present day, they have assisted in research programmes to assess the acceptability and practicability of protective equipment by, for example, investigating skin sensitivity to different mixes of rubber compounds to be used for the production of protective clothing. Also there has been considerable research into protective pre-treatments and treatments for chemical and biological agent poisoning and the effects of exposure to low doses of chemical warfare and potential threat agents. These have included mustard blister agents, organophosphate derivatives such as nerve agents, lachrymators, vomiting inductors, incapacitants and antidotes. It is this latter category of studies that has attracted most concern from the popular media and public alike.

Approximately 3,000 volunteers have participated in studies involving nerve agents and about 6,000 with mustard gas. Some individuals have been potentially exposed to both agents. Participation in such studies did not necessarily involve exposure to the agent concerned; for instance, some volunteers acted as 'control' and where protective clothing was being evaluated, this may have prevented actual exposure. It is estimated that several hundred volunteers may have been involved in studies evaluating potential therapeutic drugs and threat compounds such as lysergic acid diethylamide (LSD), sensory irritants and morphine derivatives and several tens of volunteers in studies with artificial smog.

The Porton Down Volunteers' Medical Assessment Programme (PDVMAP) was established in February 2001 as a result of a Ministry of Defence initiative to investigate the health concerns of some who took part in the volunteer trials and to assess whether or not there was evidence to support their claims. Those people felt that they were suffering unusual ill-health which might be linked to their participation in trials at Porton Down. Many had already been investigated as a result of their health concerns, either by their own general practitioners or NHS hospital medical staff.

\section{Methods}

Assessment process

Eligibility to attend the programme was based on a record of attendance by the volunteers at Porton Down, information about the studies in which they participated and subsequent health.

Before any volunteer attended the programme, a request was made to the general practitioner to have photocopies of the practice notes available for that consultation. Records were also obtained of the volunteer's visit to Porton Down so that 
the authors had the maximum possible information available before the volunteers attended. For some, a prior request was also made for military medical documents. Every effort was made to offer a patient an appointment within 5 weeks of their application to attend. Letters following their consultation were sent out within 2 days. Travel costs were met by the Ministry of Defence for attendance at the programme, as was overnight accommodation when required.

Before the consultation, patients completed a short questionnaire about their military service with particular reference to their unit, rank and trade at the time of their attendance at Porton Down. A detailed history was taken and a full clinical examination carried out. Exposures at Porton Down and any immediate effects were recorded, based on Porton Down records and patient recall. Some volunteers attended as controls for exposure groups, whilst others took part only in physiological experiments such as anthropometric measurements, blood volume measurements and respiratory physiological experiments. The patient was also given the opportunity to confirm any details that we had from his Porton Down visit - he always had a copy of the same letter.

As most of these volunteers had previously been fully investigated, no routine investigations were undertaken as a result of their visit here. On four occasions there was a clinical indication for some extra investigation to be requested. A letter describing the assessment was sent to the patient's general practitioner and copied to the patient.

Acquisition of clinical findings, database input and subsequent analysis used the same

Table 1. Sociodemographic data.

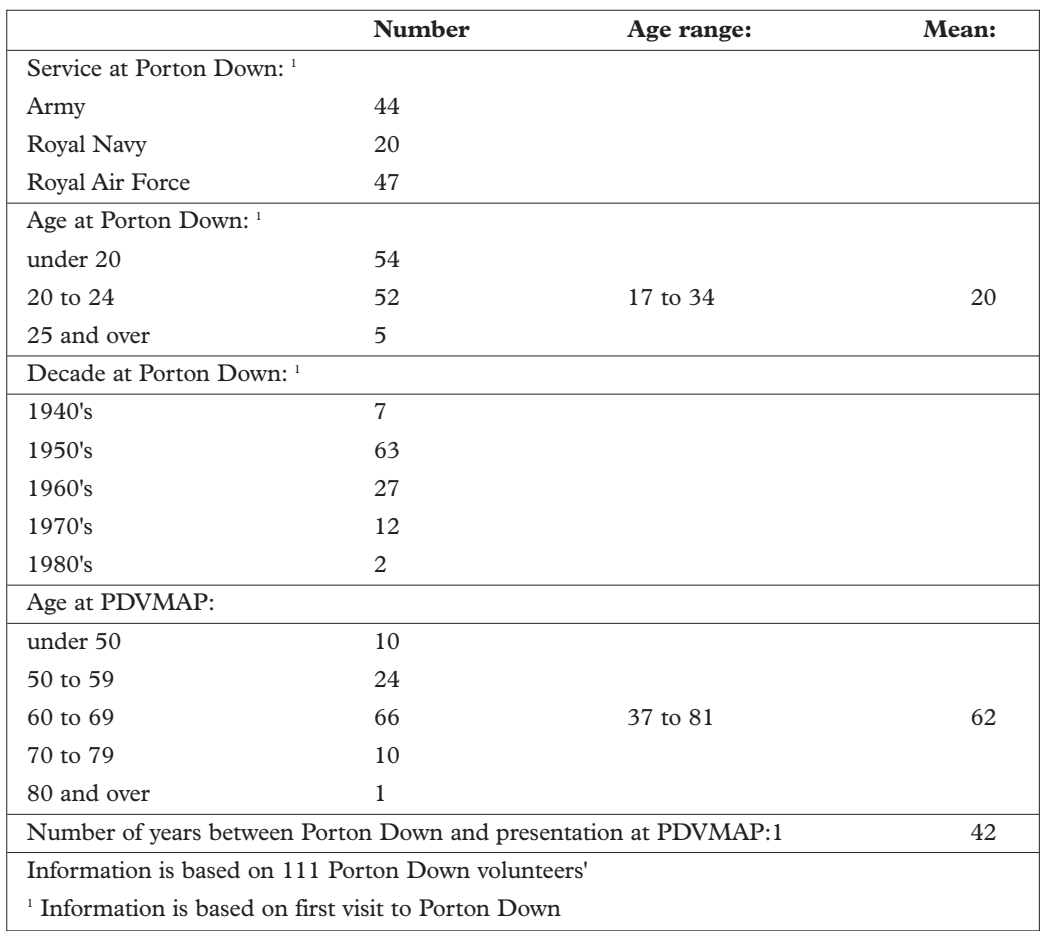

methods as when addressing health problems of Gulf War veterans $(1,2)$.

\section{Case series}

The case series comprises an analysis of the first 111 Porton Down volunteers who attended the Assessment Programme between 1 February 2001 and 30 September 2002. It was not possible, given the historical background and immediate needs for a medical assessment programme, to study a control group for this cohort. The PDVMAP is not a treatment or research centre.

\section{Diagnoses}

All volunteers were seen by one of two physicians, HAL or RG. Diagnoses were coded according to International Classification of Diseases, 10th revision (3) and this publication groups diseases in Chapters (see Clinical Findings).

\section{Results}

All case notes were available for study.

\section{Demographic characteristics of} volunteers

Table 1 presents comparative sociodemographic information of the patients seen. The mean age was $62(37-81)$ years and $59 \%$ of patients attending were in the age range (60-69). The majority of attendees went to Porton Down in the 1950s and were aged 19 at the time of attendance there. Of the 111 patients seen at the PDVMAP, 75 were in regular service at the time of their attendance, and 36 were National Servicemen. All were other ranks, except one cadet officer and one officer. Most, 96, attended Porton Down on one occasion, 11 on two occasions, and 4 on three or more occasions. All the data in Table 1 is based on information from their first visit to Porton Down. All volunteers who attended for assessment were male.

\section{Exposure data}

Table 2 presents the evidence on exposures based on data from Porton Down. Of the 111 seen, we had exposure data on 109 from Porton Down records, 70 were exposed to a variety of rubber mixes applied to forearm, 60 to sulphur mustard blister agent, 55 to nerve agents such as organophosphate derivatives (for example, sarin) and 45 to a variety of sensory and centrally acting incapacitants varying from orthochlorobenzylidene malonitrite (CS) and dibenz [b.f] - 1, 4 oxazepine (CR) riot control agents, alcohol and LSD.

Incapacitants are divided into two subgroups known as central and sensory agents. Central nervous system depressants include 3 quinuclidinyl benzilate (BZ) and other centrally acting anticholinergic drugs. Central nervous system stimulants include indoles such as LSD and cannabinols (for 
Table 2. Exposures.

\begin{tabular}{|c|c|}
\hline & Number \\
\hline Rubber mixes: & 70 \\
\hline Blister agent: & 60 \\
\hline Nerve agent: & 55 \\
\hline Incapacitant: & 45 \\
\hline Decontaminant: & 33 \\
\hline Antidote: ${ }^{1}$ & 33 \\
\hline Vapour: & 5 \\
\hline BW simulant: ${ }^{2}$ & 4 \\
\hline Irritant: & 3 \\
\hline Anti-histamine: & 1 \\
\hline Miscellaneous: & 5 \\
\hline \multicolumn{2}{|c|}{$\begin{array}{l}\text { Information is based on } 109 \text { Porton Down volunteers seen } \\
\text { at PDVMAP for whom we hold confirmed information } \\
\text { from the Porton Down records and archives } \\
{ }^{1} \text { Some patients who were not exposed to nerve agent } \\
\text { received the antidote } \\
{ }^{2} \text { Bacillus subtilis }\end{array}$} \\
\hline
\end{tabular}

example, marijuana). Sensory incapacitants are also divided into two groups viz (i) lachrymators (tear inducing agents) such as riot control agents (for example, chloroacetophenone [CN Mace]), CS and $\mathrm{CR}$ and (ii) vomiting agents which are all organic arsenic compounds (for example, diphenylaminochlorasine [DM Adamsite]). All the nerve agent exposures and most of the sulphur mustard blister agent exposures were studied in a gas chamber.

A further 33 received decontaminants after either exposure to mustard blister agent or liquid nerve agent applied to their skin. Another 33, after receiving a nerve agent, then received an antidote atropine or pralidoxime although a few received antidote only. Two were exposed to sulphur dioxide vapour as part of experiments investigating the effects of London smog on the respiratory tract and one was exposed to carbon dioxide. One was exposed to hydrogen chloride vapour and another to carbon monoxide and oxygen (lung diffusion capacity measurement). Further, a harmless bacterial agent simulant, Bacillus subtilis, was used when assessing respirator effectiveness.

Three were exposed to irritants, one to zinc naphthenate (fungicide) and pentachloraphenol (pesticide), another to a sulphonamide compound and $\mathrm{M}$ chloroacetylaminophenyldichloriarsine, and one to cantharidin (blister agent - beetle family). In the miscellaneous category, two were exposed to calcium carbonate, one to metaraminol - a vasoconstrictor, (as part of tilt table experiment), one to adrenaline and chlorine, and one to dyestuff $\mathrm{Q}$ plus cyclohexalylamine (protective clothing development).

\section{Reaction to exposures}

The majority of volunteers agreed with the descriptions of their exposures as retrieved from Porton Down records. For many, memories were faint, but they accepted that the records were broadly accurate.

The majority (54 of 64, 84\%) did not have any adverse reactions to the rubber mixes.

With respect to the sulphur mustard blister agent, based on Porton Down information and patient recall, some had local erythema, others developed local blisters and one developed a widespread vesicular eruption. Those subjected to the nerve agents all experienced very similar reactions of a tight chest, miosis, severe headaches and nausea. In these 33 volunteers for which we have recorded data, the mean fall in serum acetyl cholinesterase activity post exposure was $34 \%$ (range $0-95 \%$ ).

All exposed to riot control agents developed symptoms including rhinitis, conjunctivitis, coughing and spluttering and some wheezed. One volunteer who experienced acute nasal symptoms has these persisting long-term. Of the 2 exposed to sulphur dioxide vapour, neither ever presented with rhinitis.

All volunteers left Porton Down fully able, most going on to weekend leave before returning to military duties.

\section{Clinical findings}

Table 3 summarises the most frequently recorded diagnoses. Circulatory system diseases were the most common. Other Chapter 9 diagnoses included cardiomyopathy (1), haemorrhoids (1), mitral valve prolapse (1), oesophageal varices (1) and thromboembolic disease (1).

Next in rank order were musculoskeletal diseases (Chapter 13). The spondylosis group included degenerative joint disease (2), ankylosing spondylitis (1), cervical spondylosis (1), and lumbar spondylitis (1). Other Chapter 13 diagnoses included back pain (1), bilateral ruptured biceps-tendons secondary to osteoarthritis (1), fibromuscular pain (1), osteomyelitis (1), polymyalgia rheumatica (1), Reiter's syndrome (1), rheumatoid arthritis (1) and an unsuccessful knee replacement (1).

Chapter 10 diagnoses were the third most common group, with asthma and sinusitis (includes rhinitis 4) most frequently. Other diagnoses included bronchiectasis (1), fibrosing alveolitis (1), hayfever (1), nasal polyps (1), pleural plaques (1), recurrent chest infections (1) and sarcoidosis (1).

Fourthly were diseases of the genitourinary system with prostatic problems, other than prostate cancer, most commonly found. Others included cyclosporin nephrotoxicity (1), epididymal cyst (1), gynaecomastia (1), nephritis (1), primary male infertility (1) and urethral stricture (1).

Skin disorders were fifth in frequency. Other disorders in this Chapter 12 included acne rosacea (2), cheiropompholyx (1), chronic urticaria (1), fungal infections (1), photosensitive skin rash (1), pruritus ani (1) and skin moles (1). 
Table 3. Diagnoses.

\begin{tabular}{|c|c|c|}
\hline ICD-10 Chapter titles: & Most frequent conditions 1 & Number \\
\hline \multirow[t]{6}{*}{ 9-Diseases of the circulatory system: } & & 43 \\
\hline & Hypertension & 22 \\
\hline & Ischaemic heart disease & 17 \\
\hline & Peripheral vascular disease & 6 \\
\hline & Cerebrovascular accidents & 6 \\
\hline & Cardiac arrhythmias & 5 \\
\hline \multicolumn{2}{|c|}{ 13-Diseases of the musculoskeletal system and connective tissue: } & 29 \\
\hline & Osteoarthritis & 18 \\
\hline & Spondylosis & 5 \\
\hline \multicolumn{2}{|c|}{ 10-Diseases of the respiratory system: } & 24 \\
\hline & Asthma & 9 \\
\hline & Sinusitis & 7 \\
\hline & Chronic obstructive airways disease & 4 \\
\hline \multicolumn{2}{|c|}{ 14-Diseases of the genitourinary system: } & 22 \\
\hline & Prostatitis & 10 \\
\hline & Detrusor instability & 3 \\
\hline & Impotence & 3 \\
\hline & Renal calculi & 3 \\
\hline \multicolumn{2}{|c|}{ 12-Diseases of the skin and subcutaneous tissue: } & 21 \\
\hline & Dermatitis (non-specific) & 10 \\
\hline & Psoriasis & 3 \\
\hline \multirow[t]{7}{*}{ 11-Diseases of the digestive system: } & & 18 \\
\hline & Diverticulosis & 4 \\
\hline & Duodenal ulcer & 4 \\
\hline & Hiatus hernia & 4 \\
\hline & Dental caries & 3 \\
\hline & Irritable bowel syndrome & 2 \\
\hline & Ulcerative colitis & 2 \\
\hline \multirow[t]{6}{*}{ 6-Diseases of the nervous system: } & & 18 \\
\hline & Sleep apnoea & 5 \\
\hline & Epilepsy & 3 \\
\hline & Carpal tunnel syndrome & 2 \\
\hline & Demyelinating disorder & 2 \\
\hline & Parkinsons' disease & 2 \\
\hline \multirow[t]{5}{*}{ 2-Neoplasms: } & & 18 \\
\hline & Colon malignancies & 5 \\
\hline & Skin cancers & 4 \\
\hline & Cancer of bladder & 2 \\
\hline & Sarcoma & 2 \\
\hline \multirow[t]{2}{*}{ 7-Diseases of the eye and adnexa: } & & 14 \\
\hline & Cataracts & 7 \\
\hline \multicolumn{2}{|c|}{ 4-Endocrine, nutritional, and metabolic diseases: } & 13 \\
\hline & Diabetes mellitus & 12 \\
\hline \multicolumn{2}{|c|}{ 5-Mental and behavioural disorders: } & 13 \\
\hline & Depression & 8 \\
\hline & Anxiety state & 5 \\
\hline
\end{tabular}

Diseases of the digestive system were next most commonly seen. Others in Chapter 11 included cryptogenic cirrhosis (1), reflux oesophagitis (1) and sclerosing cholangitis (1).

Next were disorders of the nervous system. Others included tension headaches (2), benign essential tremor (1), dementia (1), neuropathic pain (1) and thalamic pain (1).

The most frequent Chapter 2 diagnoses are shown in Table 3 . The skin cancers included basal cell carcinoma (3), melanoma (1) and squamous papilloma (1). The colon malignancies included colon adenomata (1), colon polyps (1) and colon cancer (1). The others are cancer of prostate (1), chronic lymphatic leukaemia (1), myelodysplasia (1), teratoma (1) and vocal cord cancer (1).

The most common Chapter 7 diagnosis was cataracts. Others were blepharitis (1), retinal haemorrhage (1) and unspecified disorder of sclera (1). Visual changes included diplopia (1), myopia (1), presbyopia (1) and tunnel vision (1).

Of Chapter 4 diagnoses, diabetes mellitus (12) was the most common with 3 of the patients being overweight (BMI 25-29.9) and 9 obese $(\mathrm{BMI} \geq 30)$. There was one case of thyrotoxicosis.

Other Chapter 5 diagnoses (mental and behavioural disorders) included alcohol abuse (2), adjustment disorder (1), personality disorder (1) and somatoform autonomic dysfunction (1). There were 3 cases of no formal psychiatric diagnosis (2).

There were other infrequent miscellaneous diagnoses that are not shown in Table 3. Chapter 21 were those that were well with no diagnoses but concerns, though one had arthrodesis and one had suffered a bereavement reaction. Chapter 8 (ear diseases) included tinnitus (3), deafness (2), sensorineural deafness (1), mastoiditis (1) and Menière's disease (1). Chapter 1 (infectious disease) included meningoencephalitis (1), pulmonary tuberculosis (1) and tinea cruris (1). Amputation following a brachial plexus injury (1), back injury (1) and neuropraxia due to dislocation of the shoulder (1) were covered in Chapter 19 (injury). Chapter 17 (congenital malformations) contained kidney horseshoe (1) and ureteric diverticulum (1). Chapter 18 (symptoms and signs) included unexplained sensory features (1) and vertigo (1). Chapter 3 (blood diseases) consisted of polycythaemia (1).

Figures 1 and 2 show exposures and disease condition related to the age of volunteers. The calculation of disease rates for these subjects was not undertaken because of the small number and that they were selfselected. These figures clearly show there is an age, but not exposure, relationship to diseases recorded.

Three volunteers who were not exposed to any substances served as controls. They had undergone physiological measurements and/ or acted as controls for nerve agent exposure. They had diagnoses of: diabetes mellitus, osteoarthritis and anxiety neurosis (1), ischaemic heart disease, hypertension and hiatus hernia (1) and diabetes mellitus, ischaemic heart disease, cerebrovascular disease, thalamic pain and urticaria (1).

\section{Symptoms}

We have analysed the symptoms with which patients presented to determine whether they were disease related or could have some other explanation. The frequency of symptoms and their rank order is shown in Figure 3. $17 \%$ of patients were totally 

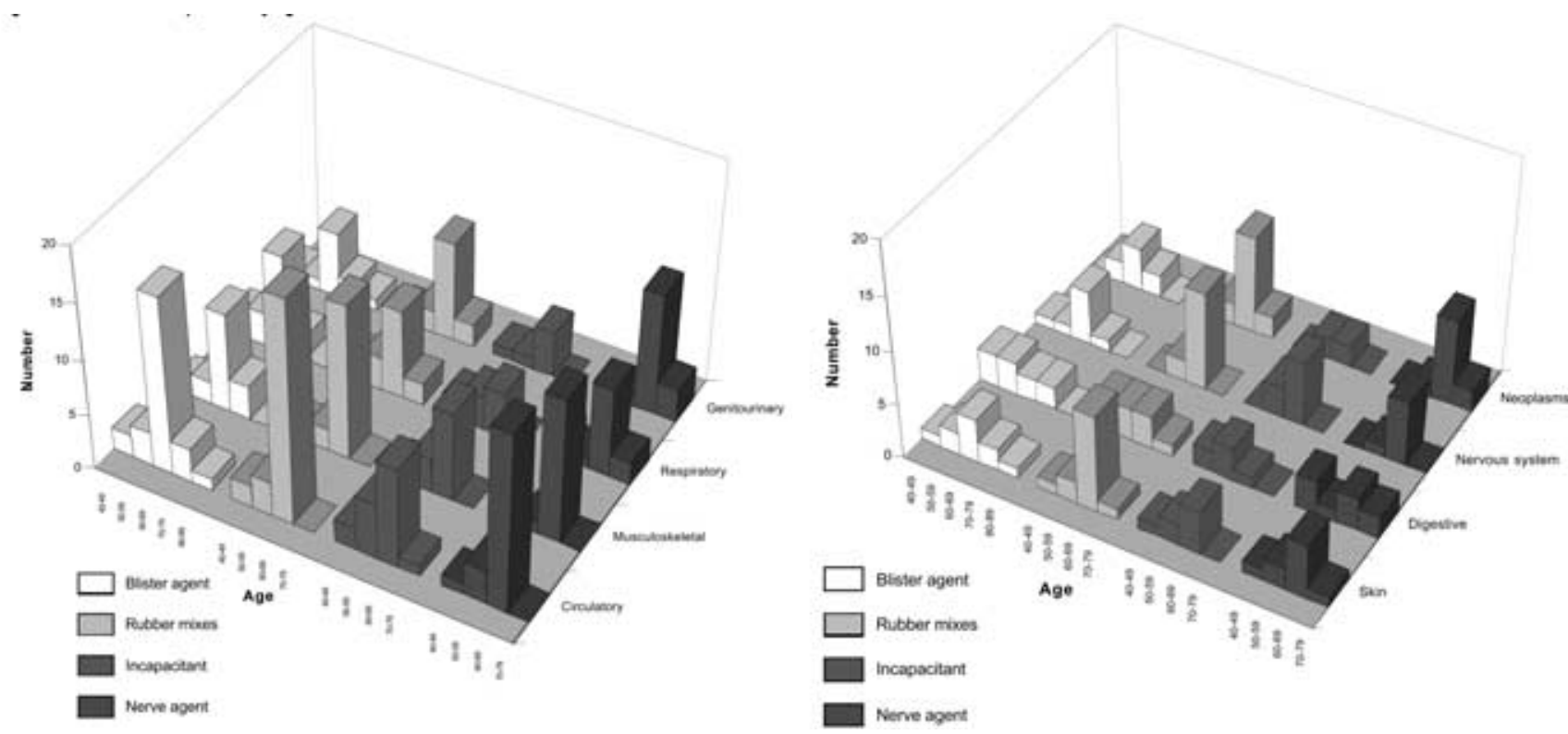

Fig 1. Disease and exposure by age.

Fig 2. Disease and exposure by age.

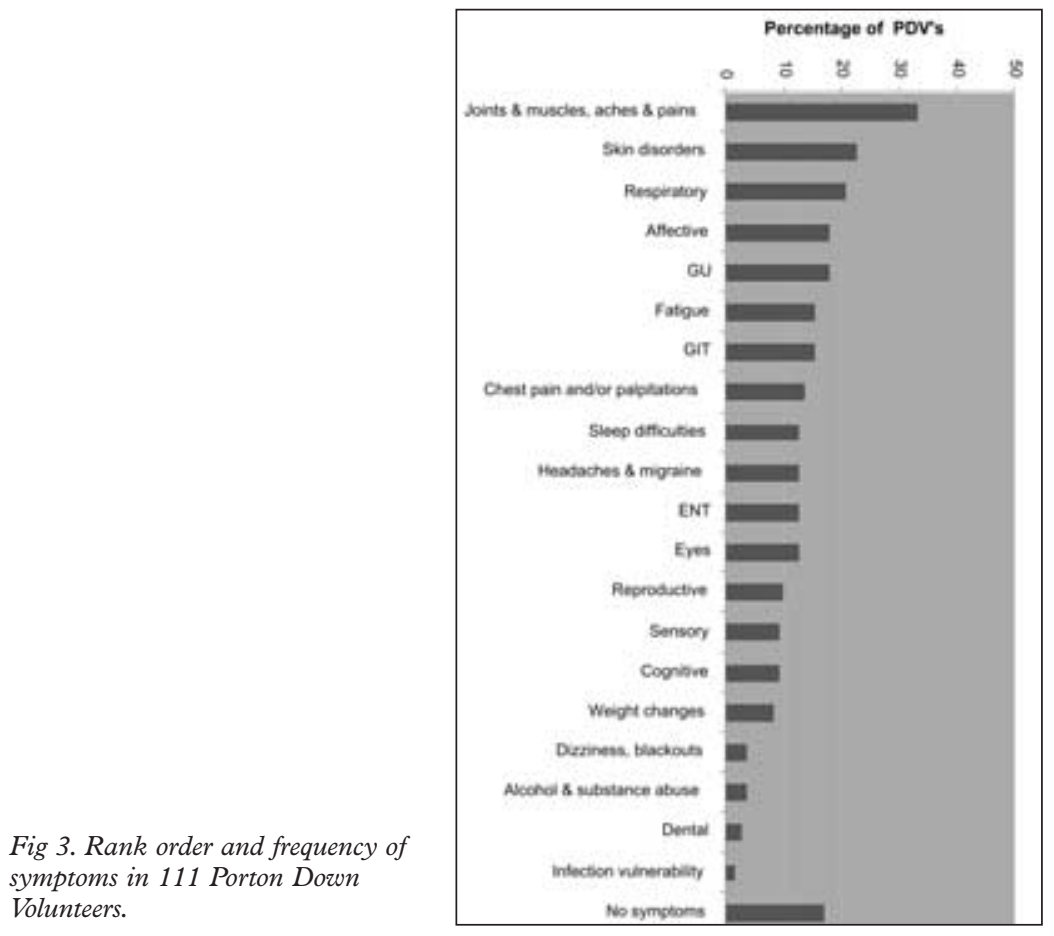

Volunteers.

No symptoms

asymptomatic. Figure 4 clearly shows that most symptoms (88\%) were readily explicable on a disease related basis.

\section{Discussion}

We report here an analysis of the first 111 volunteers seen at this unit. With the high quality data we received both from GPs and Porton Down, some generalisations are permissible. We realise that the majority of volunteers attending were in the age group $60-69$, but this does not obviate our finding of no unusual pattern of disease from that expected. Further, the mean time between the volunteers' visit to the Medical Assessment Programme was 42 years after their visit to Porton Down and most unlikely to be related to the single low dose exposures they received there. Most were exposed to single, low doses of the various agents shown in Table 2. There is little, if any, literature to support the development of long term illhealth as a result of such single, low dose exposures.

Even three volunteers who were not exposed to any toxic agents had diseases similar to others who had been exposed, but were nevertheless age related. In each case, symptoms were explicable on known clinical diagnoses.

The reactions described by volunteers at the time of exposures are compatible with the nature of the single low dose exposure they received (4). Some had more than one single low dose exposure, but always at significant time intervals so that cumulative effects were minimised. Although some had acute reactions, importantly all left unaided and returned to their units, either immediately or after weekend leave. This is very different from the consequences of long term repeated exposures or to single high dose exposure to

${ }_{1}$ Non-disease related symptoms refer to those that could not be related to a specific disease and were therefore not explicable in medical diagnostic terms.

Fig 4. Percentage of disease related symptoms in 111 Porton Down Volunteers agents such as mustard gas or organophos- 
phate nerve agents (5-8).

It became clear at interview that many volunteers were unsure whether or not the substances to which they were exposed at Porton Down could still be (a) present in their bodies or (b) responsible for any illnesses subsequently developed. After careful explanation by the physician they saw, the large majority left fully satisfied (a) that their current health problems were probably not due to exposures at Porton Down and (b) their future health or that of their families or children would equally not be affected by what happened at Porton Down. These statements are justified by the patient satisfaction questionnaire response of $100 \%$.

Many stated that they had not been given sufficient explanation at the time as to what might be the nature of their exposures.

Unlike other studies $(1,2,9)$ with Gulf veterans and civilians (10) addressing the problem of multiple unexplained physical symptoms, our patients had symptoms which were explicable on the basis of known diagnoses. However, the $12 \%$ whose symptoms could not be explained on the basis of organic diseases are very similar to patients presenting to their general practitioners $(10,11)$.

There is not any unusual pattern of disease amongst volunteers whose mean age is 62 . Further, the time between the volunteers' visit to MAP in most cases is after a significant period of 42 years since their visit to Porton Down and highly unlikely to be related to the low dose exposures they received there.

The mean time between attendance at Porton Down and establishing diagnoses about which the patients complained of regarding their Porton Down visit was 30 years, as per evidence provided to PDVMAP physicians at the time of PDV attendance. In all examples the time interval between exposure to an agent at Porton Down and development of the specific diagnosis is of such an interval as to make any possible connection between exposure and disease development most unlikely.

\section{Conclusion}

An analysis of 111 self-selected Porton Down volunteers who have attended this unit between 1 February 2001 and 30 September 2002 has not shown any unusual pattern of disease. No links have been recognised between original exposures and subsequent health, with the possible exception of 1 case of rhinitis. The diseases present in this cohort and their frequency is what a competent body of medical or scientific opinion would expect in members of the UK general public of similar age.

\section{References}

1. Lee HA, Gabriel R, Bale AJ, Bolton P et al. Clinical findings of the second 1000 UK Gulf War Veterans who attended the Ministry of Defence's Medical
Assessment Programme. JRAMC 2001;147:15360.

2. Lee HA, Gabriel R, Bolton P, Bale AJ, Jackson M. Health status and clinical diagnoses of $3000 \mathrm{UK}$ Gulf War Veterans. FRSM 2002;95:91-97.

3. ICD-10 International Statistical Classification of Diseases and Related Health Problems (10th Revision) 1992; Vol 1, WHO, Geneva.

4. Marrs TC, Maynard RL, Sidell FR. Chemical Warfare Agents. Toxicology and treatment. 1996; Publ. John Wiley \& Sons, Chichester.

5. Bullman T, Kang H. A fifty year mortality followup study of veterans exposed to low level chemical warfare agent, mustard gas. AEP 2000;100,No 5:333-38.

6. Organophosphate sheep dip. Clinical aspects of long term low dose exposure. Report of a Joint Working Party of the Royal College of Physicians and Royal College of Psychiatrists. 1998; CR67.

7. Evison D, Hinsley D, Rice P. Chemical weapons. BMF 2002;324:332-335.

8. Karralliedde L, Wheeler H, Maclehose R, Murray V. Possible immediate and long-term health effects following exposure to chemical warfare agents. Public Health 2000;114:238-48.

9. Unwin C, Blatchley NF, Coker WJ et al. The health of United Kingdom Servicemen who served in the Persian Gulf War. Lancet 1999;353:169-78.

10. Katon WJ, Walker EA. Medically unexplained symptoms in primary care. FClinPsychiatry 1998;59(suppl20):15-21.

11. What to do about medically unexplained symptoms. Drug Therapeut Bull 2001;39:5-7.

\section{Key messages}

- Porton Down volunteers were exposed to single low dose concentrations of chemical exposures.

- Some developed the expected symptoms from such exposures, but all left Porton Down well.

- No correlation has been found between low dose exposures and development of later health problems. Diseases seen were as one would expect to find in a cohort of men with a mean age of 62 .

- In nearly all volunteers, symptoms complained of related to established diagnoses.

- No unusual pattern of disease has emerged amongst the cohort of volunteers medically assessed compared to those of the general population of the same age.

\section{Policy implications}

- This small study in depth suggests that ex-Porton Down volunteers need not have any fears that their health has been affected by attendance at Porton Down.

- Better risk communication to volunteers at the time of medical trials will help to allay any later health concerns.

\section{List of abbreviations}

MOD = Ministry of Defence

PDV = Porton Down Volunteers

PDVMAP = Porton Down Volunteers'

Medical Assessment Programme

LSD = lysergic acid diethylamide

$\mathrm{CS}=$ orthochlorobenzylidene malonitrite

$\mathrm{CR}=$ dibenz $[\mathrm{b} . \mathrm{f}]-1,4$ oxazepine

$\mathrm{CN}$ Mace $=$ chloroacetophenone

DM Adamsite $=$ diphenylaminochlorasine 